O impacto do orçamento impositivo de emendas parlamentares individuais e coletivas no

Presidencialismo de Coalizão. Revista Ensaios, vol. 15, jul-dez de 2019.

\title{
O impacto do orçamento impositivo de emendas parlamentares individuais e coletivas no Presidencialismo de Coalizão.
}

Resumo: As emendas parlamentares são encaradas como um mecanismo de articulação entre os poderes Executivo e Legislativo dentro da lógica do Presidencialismo de Coalizão. Portanto, alterações sobre as matérias que regulamentam a mesma são sempre um foco de análise que colocam em questão a governabilidade. No presente artigo, serão analisadas duas emendas à Constituição que tornaram a emenda parlamentar individual e a de bancada um orçamento impositivo. As PEC 86/2015 e a 34/2019, abrem caminho para uma série de implicações sobre a redução do poder do Chefe do Executivo por meio desse tradicional mecanismo. No presente trabalho, serão revisitadas as teorias de Figueiredo e Limongi (2002) que refutam essa hipótese de emenda como moeda de troca e apresentam uma arena para discutir essa temática sob a luz das organizações partidárias.

Palavras-chave: Orçamento Impositivo; Presidencialismo de Coalizão; Emenda Parlamentar.

\section{The impact of the imposing budget of individual and collective parliamentary amendments on Coalition Presidentialism.}

Abstract: The parliamentary amendments are seen as a mechanism of articulation between the Executive and Legislative powers within the logic of Coalition Presidentialism. Therefore, changes on the matters that regulate it are always a focus of analysis that will question governance. In this article, two amendments to the Constitution that make the individual and bench parliamentary amendment into a tax budget will be analyzed. PEC 86/2015 and 34/2019 paves the way for a number of implications for reducing the power of the Chief Executive through this traditional mechanism. In the present work, the theories of Figueiredo and Limongi (2002) that refute this amendment hypothesis as exchange currency will be revisited and presents an arena to discuss this issue under the light of the party organizations.

Keywords: Tax Revenue; Coalition Presidentialism; Parliamentary Amendment.

\footnotetext{
${ }^{1}$ Graduada em Ciências Sociais na Universidade Federal do Rio de Janeiro (UFRJ), Rio de Janeiro, RJ, Brasil.paulafriasds@gmail.com.
} 
O impacto do orçamento impositivo de emendas parlamentares individuais e coletivas no

Presidencialismo de Coalizão. Revista Ensaios, vol. 15, jul-dez de 2019.

O presidencialismo de coalizão e os mecanismos que o inviabiliza é tema de muitas discussões dentro da literatura política. Por mais que alguns autores tentem apontar o caso brasileiro como singular, muitos empreendem esforços em compará-los com democracias já estabilizadas, a fim de não cair em um determinismo que estabelece relações de correlação que não são causais.

Um dos mecanismos que possibilitam o presidencialismo de coalizão, dentro do sistema brasileiro, são as emendas parlamentares. Elas são articuladas dentro das teorias institucionalistas como forma de barganha entre os deputados e o chefe do Executivo Federal. Essa afirmação assume alguns pressupostos normativos que os próprios autores não questionam. Elas adotam uma postura determinista, e por vezes utilitarista, ao afirmarem que todos os efeitos da prática política estão subordinados apenas às configurações institucionais. Há uma falta de diálogo entre teorias institucionalistas, uma teoria política clássica que poderia nortear aos aspectos normativos das instituições e uma sociologia política, que pode localizar outros atores sociais no arranjo funcional da política.

O presente trabalho vai propor um debate entre as teorias que colocam as emendas parlamentares em um lugar de "moeda de troca", e as formulações empíricas e teóricas que Figueiredo e Limongi desenvolvem desde o início do século para refutar esse princípio. A partir desse debate, as seções serão concluídas para refletir sobre como essa mudança na execução das emendas parlamentares pode afetar ou não o presidencialismo de coalizão.

\section{1) O presidencialismo e suas supostas amarras:}

O sistema político da República Federativa Brasileira é alvo de uma série de discussões que vão desde uma crença do fracasso auto realizável (MAINWARING, 
O impacto do orçamento impositivo de emendas parlamentares individuais e coletivas no

Presidencialismo de Coalizão. Revista Ensaios, vol. 15, jul-dez de 2019.

1993) ${ }^{2}$ até à uma saída da caverna através do presidencialismo de coalizão (ABRANCHES, 2018).

Nesta seção, serão abordadas alguma das características que rodeiam o sistema brasileiro, que possui em suas facetas o presidencialismo, o multipartidarismo, um sistema proporcional de voto com lista aberta e o federalismo. O presidencialismo é alvo da crítica clássica de que ele por si só é produtor de uma paralisia decisória (MAINWARING, 1993). Essa relação direta é operada fazendo-se um contraponto ao parlamentarismo. Neste último, o primeiro ministro necessariamente possuiria um apoio majoritário no legislativo, pois foi por essa via que chegou ao seu cargo. Esse fato concatenado com o multipartidarismo seria fadado a paralisia segundo essa lógica, pois o multipartidarismo é assumido como a sombra da representatividade e a mesma é vista em um trade-off ${ }^{3}$ com a governabilidade.

O que essa teoria não questiona é que para se chegar a um consenso dentro do parlamento são necessárias coalizões prévias, mecanismo este, usado pelo presidencialismo brasileiro, como é apontado por Abranches (1988). De acordo com Oliveira e Viana (2018), as taxas de sucesso e de dominância no caso brasileiro são muito similares aos países parlamentaristas com uma democracia consolidada, ou seja, eles argumentam que as críticas ao presidencialismo como fator de paralisia não condizem com a realidade que o presidencialismo de coalizão opera, pois este oferece mecanismos possíveis à governabilidade. Há uma correlação entre o status da coalizão e o sucesso legislativo do Executivo.

Para Abranches (2018), os poderes legislativo e executivo articulam-se entre si através de alguns mecanismos institucionais que permitem uma coalizão, como por exemplo, através de loteamento de cargos nos Ministérios e a distribuição de emendas

\footnotetext{
${ }^{2}$ Em seu texto o autor afirma: "Diversas características do sistema eleitoral contribuíram para a formação de um sistema multipartidário fragmentado em que o partido do presidente quase nunca tem maioria no Congresso. A situação do presidencialismo em minoria permanente leva facilmente a impasses entre o executivo e o legislativo, que resultam em imobilismo político (Mainwaring, no prelo). Devido ao calendário eleitoral rígido do sistema presidencialista, não existem meios institucionais para lidar com essa situação de presidentes que não dispõem de sustentação estável no Congresso.”(MAINWARING, 1993)

${ }^{3}$ Resolução de um problema em detrimento de outro. Uma relação inversamente proporcional.
} 
O impacto do orçamento impositivo de emendas parlamentares individuais e coletivas no

Presidencialismo de Coalizão. Revista Ensaios, vol. 15, jul-dez de 2019.

parlamentares. A coalizão permite que cada um dos poderes consiga aprovar seus projetos de governo.

No contexto nacional, é importante frisar uma característica do tecido social que explica um pouco o modus operandi dos atores políticos: as elites locais e as elites nacionais. Para Vianna, Carvalho e Bignotto (2000), esses dois grupos considerados hegemônicos estão em embate na arena política. As elites nacionais atuam como uma força centrípeta e estão concentradas no Poder Executivo, elas estão associadas à projetos de modernização. Já as elites locais, atuam como força centrífuga e possuem compromisso com o atraso, a fim de manter seus privilégios e gerar um contexto favorável ao seu patrimonialismo. Essas elites concentram-se no legislativo, já que estabelecem uma relação de clientelismo com as populações locais.

Abranches (2018) também aponta para os dispositivos constitucionais que permitem um duplo processo de centralização. No poder Executivo, essa centralização se reflete no poder de agenda que o presidente possui, o uso da medida provisória e suas prerrogativas sobre lei orçamentária e matéria tributária. Já o poder legislativo, centraliza o seu poder nas figuras dos líderes de partido, líderes de comissões e líderes das casas.

Todas essas conclusões podem ser mobilizadas na criação de diversas hipóteses sobre o que influencia os atores político nas votações, nos seus discursos e nos seus posicionamentos informais. Algumas linhas de pensamento afirmam que os políticos são office seeking, ou seja, são motivados exclusivamente pelo desejo de alcançar cargos e recursos. Para Freitas (2013, p.42), essa característica não seria suficiente para sustentar a coalizão, pois "uma vez que os parlamentares buscam unicamente seus interesses individuais, supõe-se que não há nenhum ator ou instituição que seja capaz de frear a busca por esses interesses".

Todos esses conceitos serão articulados mais à frente para entender a argumentação que relaciona as emendas parlamentares com "moeda de troca".

\section{2) Emendas parlamentares e suas transformações pós-88:}


O impacto do orçamento impositivo de emendas parlamentares individuais e coletivas no

Presidencialismo de Coalizão. Revista Ensaios, vol. 15, jul-dez de 2019.

A fim de maior inteligibilidade no que tange às questões orçamentárias das emendas parlamentares e os conflitos políticos econômicos embutidos nelas, será feito um panorama das regulamentações que este dispositivo sofreu desde a Carta de 88, assim como, suas implicações no jogo político.

As chamadas emendas parlamentares, tratam-se de emendas ao orçamento Geral da União.

\begin{abstract}
são propostas por meio das quais os parlamentares podem opinar ou influir na alocação de recursos públicos em função de compromissos políticos que assumiram durante seu mandato, tanto junto aos estados e municípios quanto a instituições. Tais emendas podem acrescentar, suprimir ou modificar determinados itens (rubricas) do projeto de lei orçamentária enviado pelo Executivo (SENADO NOTÍCIAS, 2019).
\end{abstract}

A Lei Orçamentária Anual (LOA) é enviada pelo Executivo para o Congresso apreciar e os deputados podem fazer modificações que serão votadas na Comissão Mista de Planos, Orçamentos Públicos e Fiscalização (CMO).

As emendas podem ser de três tipos: individuais, coletivas e de relatores. Contudo, neste trabalho, serão analisados os dois primeiros tipos. Ambas foram e estão sendo alvo de projetos de emendas à Constituição que as tornam impositivas.

A Resolução no 2/95-CN estabeleceu que "a distribuição de recursos entre os parlamentares passou a ser uniforme e fixa, retirando do relator geral a possibilidade de favorecer este ou aquele grupo na repartição desses recursos." (FIGUEIREDO \& LIMONGI, 2002, p.315). A Resolução foi produto da CPI do orçamento de 1993. Com isso, a fase de negociação envolvendo as emendas seria transferida do momento da votação na CMO para as mãos do Executivo Nacional que decidiria sobre sua execução. Atualmente, qualquer deputado pode apresentar emendas aos projetos que estejam tramitando na comissão, no que se refere à medidas provisórias, $\mathrm{PPA}^{4}$, créditos adicionais, LDO $^{5}$ e LOA.

\footnotetext{
${ }^{4}$ Plano Plurianual.

${ }^{5}$ Lei das Diretrizes Orçamentárias.
} 
O impacto do orçamento impositivo de emendas parlamentares individuais e coletivas no

Presidencialismo de Coalizão. Revista Ensaios, vol. 15, jul-dez de 2019.

No ano de 2015, diante de um cenário político instável, foi aprovada a PEC 86/2015, que institui mudanças em relação às emendas parlamentares individuais. Tendo acrescentado, entre outros, o seguinte parágrafo:

\begin{abstract}
$\S$ 11. É obrigatória a execução orçamentária e financeira das programações a que se refere o $\S 9^{\circ}$ deste artigo, em montante correspondente a 1,2\% (um inteiro e dois décimos por cento) da receita corrente líquida realizada no exercício anterior, conforme os critérios para a execução equitativa da programação definidos na lei complementar prevista no $\S 9^{\circ}$ do art. 165 (BRASIL, 1988).
\end{abstract}

A partir dessa emenda constitucional, as emendas parlamentares individuais passaram a ter uma obrigatoriedade em sua execução, podendo ser contingenciada pelo executivo, tão somente, diante de justificativas técnicas. Instalando assim o que chamase de orçamento impositivo.

A execução do orçamento pode assumir o caráter autorizativo ou impositivo. No primeiro caso, o Executivo possui discricionariedade sobre o momento e sobre o status de execução da emenda. Em outras palavras, ele tem prerrogativa para contingenciar ou não aplicar o recurso previsto. No caso de orçamentos impositivos, há uma obrigatoriedade na execução desse orçamento, podendo ser impedido apenas diante de justificativas técnicas, como está especificado no parágrafo 12 do artigo 166 da Constituição Federal (1988): “As programações orçamentárias previstas no $\S 9^{\circ}$ deste artigo não serão de execução obrigatória nos casos dos impedimentos de ordem técnica".

Em abril de 2019, o Deputado Federal Hélio Leite propõe a PEC 34/2019, que cria uma aderência ao orçamento impositivo por parte das emendas de bancada parlamentar estadual e distrital. O texto foi rapidamente aprovado em plenário e foi promulgado no mês de junho do mesmo ano. A agilidade no processo demonstra um encontro de interesses entre parlamentares antagônicos.

A passagem das emendas parlamentares de uma característica autorizativa, dominada pelo Chefe do Executivo, para um caráter impositivo, é a chave da discussão acerca do espaço que as emendas parlamentares ocupam na negociação entre os dois poderes. 
O impacto do orçamento impositivo de emendas parlamentares individuais e coletivas no

Presidencialismo de Coalizão. Revista Ensaios, vol. 15, jul-dez de 2019.

\title{
3) As emendas parlamentares como "moeda de troca":
}

O surgimento das emendas constitucionais listadas acima criou logo um ambiente de apreensão em relação à uma possível paralisia decisória. Para Pereira e Muller (2002, p. 267), a execução de emendas parlamentares individuais trata-se "de um dos mecanismos mais importantes de que o Executivo dispõe para negociar suas preferências com sua coalizão no Congresso".

É a via interpretativa do office seeking que sustenta a hipótese de que emendas parlamentares individuais são suficientes para garantir uma negociação direta dos deputados com o executivo. Essa chave não considera a força organizacional dos partidos políticos. Nessa linha, a execução de emendas parlamentares têm uma relação de causalidade com apoio às decisões do executivo.

Em seu artigo, os autores afirmam:

\begin{abstract}
As evidências apresentadas neste artigo demonstram que o presidente da República recompensa os parlamentares que sistematicamente votam a favor dos projetos de interesse do governo, autorizando a execução de suas emendas individuais, e, ao mesmo tempo, pune os que não votam nesses projetos simplesmente não executando as emendas propostas por eles. $\mathrm{O}$ artigo afirma ainda que, mantidas constantes as demais condições, quanto maior o valor das emendas executadas de um congressista, maiores são suas chances de reeleição (Pereira, 2000; Pereira e Rennó, no prelo), (PEREIRA \& MULLER, 2002, p. 274).
\end{abstract}

Essa afirmação assume alguns pressupostos normativos acerca do funcionamento do presidencialismo de coalizão e das motivações dos atores políticos envolvidos. Através dos conceitos mobilizados na primeira seção do artigo, é possível mobilizar melhor esses pressupostos. O primeiro, é de que a execução de emendas parlamentares possui uma relação de causalidade direta com a reeleição e que os candidatos são necessariamente office seeking. O segundo pressuposto desta teoria é de que os poderes legislativo e executivo possuem agendas opostas e o terceiro ponto é de que o Executivo prioriza as suas prerrogativas legislativas em detrimento das orçamentárias.

Figueiredo e Limongi (2002) analisam as taxas de execução das Emendas Individuais e cruzam esses dados com o nível de apoio às pautas do Executivo, a fim de fazer uma refutação à esses ideais normativos. Em suas conclusões, os resultados 
O impacto do orçamento impositivo de emendas parlamentares individuais e coletivas no

Presidencialismo de Coalizão. Revista Ensaios, vol. 15, jul-dez de 2019.

apontam que não há uma correlação entre essas duas variáveis no que tange aos candidatos individualmente, mas quando estes são agregados pelos seus respectivos partidos dentro da análise, há uma correlação. Para os autores, "a execução das emendas individuais é ditada por critérios político-partidários" (FIGUEIREDO \& LIMONGI, 2005, p. 746)

Essa demonstração empírica da falta de correlação entre execução de emendas e sucesso da coalizão, qualificam a análise teórica em torno dos três pressupostos citados acima. O primeiro é o que se refere às intenções dos atores políticos envolvidos. Para Freitas (2013, p. 46) “Coalizões são formadas por razões pragmáticas e óbvias: aumentar as chances de aprovar projetos ou uma agenda no Legislativo. São, portanto, e por si só, um forte indicativo de que há uma preocupação com a aprovação de políticas." A autora defende que os parlamentares, na verdade, adotam uma postura policy seeking.

Para alcançar seus objetivos, políticos têm que mudar o status quo. Mesmo que queiram apenas levar benefícios concentrados para seus eleitores e financiadores de campanha, parlamentares só serão capazes de realizar esse objetivo através da feitura de políticas. (FREITAS, 2013, p. 46).

O segundo pressuposto é amplamente discutido no subcapítulo "Conflito Inerente", da tese de Freitas. A autora postula em um dos argumentos que sustenta esse conflito inerente entre os dois poderes que a unidade de análise usada para analisar o parlamentarismo, são os partidos e no caso do presidencialismo, são os indivíduos; O que determinaria a natureza dessa relação é a força institucional dos partidos e a capacidade que esses teriam de coagir seus membros a determinados comportamentos." (FREITAS, 2013, p.33).

Tanto as conclusões citadas acima de Figueiredo e Limongi, quanto a conclusão da própria tese de Freitas, apontam que é possível ter partidos fortes em um sistema presidencialista. A disciplina partidária brasileira é um sinal dessa força. Para Limongi (2006, p17).“Coalizões obedecem e são regidas pelo princípio partidário.”.

No pressuposto que se refere aos sacrifícios das agendas do Executivo, Figueiredo e Limongi (2005, p. 759) afirmam que:

Essa tese depende ainda de que o Executivo tenha duas agendas, a legislativa e a orçamentária, e que elas sejam suficientemente independentes para permitir 
O impacto do orçamento impositivo de emendas parlamentares individuais e coletivas no

Presidencialismo de Coalizão. Revista Ensaios, vol. 15, jul-dez de 2019.

\begin{abstract}
que o apoio a uma possa ser compensado pelas perdas na outra. Compra-se apoio na esfera legislativa sacrificando-se a agenda orçamentária. A agenda legislativa é tratada como se pertencesse à esfera das escolhas de política, enquanto as decisões referentes ao orçamento são tratadas como transferências de utilidades sem que seja feita uma conexão entre ambas.
\end{abstract}

E prosseguem afirmando que:

Para que esse argumento fosse válido, ou as duas agendas, legislativa e orçamentária, teriam de ser independentes - isto é, as preferências em uma não afetariam as preferências na outra -, ou os atores não perceberiam as interrelações entre ambas (FIGUEIREDO \& LIMONGI, 2005, p. 760).

Em suma, "Se a execução de emendas individuais fosse a moeda usada para obter apoio, o presidente deveria privilegiar a execução dessas emendas e contingenciar as coletivas. Os cortes das emendas individuais, portanto, segue menos uma lógica política e mais a macroeconômica.” (FIGUEIREDO \& LIMONGI, 2002, p. 325).

\title{
4) Considerações finais:
}

O presidencialismo de coalizão oferece ao poder Executivo uma Executive Toolbox que estaria "à disposição da presidência para lidar com o contexto institucional, histórico e cultural de cada país.” (OLIVEIRA \& VIANA, 2018, p. 19). A promulgação da PEC de 2015, sobre as emendas individuais, pode ter suas implicações analisadas dentro do debate que Figueiredo e Limongi propõem. O que fica como fio condutor para futuras investigações são as implicações do orçamento impositivo sobre emendas coletivas (PEC 34/2019). Contudo, o debate pode ser mobilizado pela via da análise partidária, já que se chegou à conclusão de que os partidos são atores endógenos ao sistema decisório do presidencialismo de coalizão.

Recebido em 20/08/2019. Aprovado em 17/05/2020 
O impacto do orçamento impositivo de emendas parlamentares individuais e coletivas no

Presidencialismo de Coalizão. Revista Ensaios, vol. 15, jul-dez de 2019.

\section{Referências bibliográficas:}

ABRANCHES, Sérgio HH de. Presidencialismo de coalizão. Dados, v. 31, n. 1, p. 16$22,1988$.

Presidencialismo de Coalizão: raízes e evolução do modelo político brasileiro. Editora Companhia das Letras, 2018.

BRASIL. . Constituição da República Federativa do Brasil de 1988. Brasília, DF: Presidência da República, [2016]. Disponível em: http://www.planalto.gov.br/ccivil_03/constituicao/constituicao.htm. Acesso em: 23 de Junho de 2019.

Emendas ao Orçamento. Senado Notícias, Brasília. Disponível em: https://www12.senado.leg.br/noticias/glossario-legislativo/emendas-ao-orcamento.

Acesso em: 23 de Junho de 2019.

FIGUEIREDO, Argelina; LIMONGI, Fernando. Incentivos eleitorais, partidos e política orçamentária. Dados, v. 45, n. 2, p. 303-344, 2002.

- Processo orçamentário e comportamento legislativo: emendas individuais, apoio ao Executivo e programas de governo. Dados-Revista de Ciências Sociais, v. 48, n. 4, 2005.

FREITAS, Andréa Marcondes de. O presidencialismo da coalizão. 2013. Tese de Doutorado. Universidade de São Paulo.

LIMONGI, Fernando. Presidencialismo, coalizão partidária e processo decisório. Novos Estudos Cebrap, v. 76, p. 17-41, 2006.

MAINWARING, Scott. Democracia presidencialista multipartidária: o caso do Brasil. Lua Nova: revista de cultura e política, n. 28-29, p. 21-74, 1993.

OLIVEIRA, Vitor S. L; VIANA, João Paulo S. L. In: Governabilidade / org. Humberto Dantas. —— Rio de Janeiro :Konrad Adenauer Stiftung, 2018.

PEREIRA, Carlos; MUELLER, Bernardo. Comportamento estratégico em presidencialismo de coalizão: as relações entre Executivo e Legislativo na elaboração do orçamento brasileiro. Dados, v. 45, n. 2, p. 265-301, 2002.

VIANNA, Luiz Werneck; CARVALHO, Maria Alice Rezende de; BIGNOTTO, Newton. República e civilização brasileira. Pensar a República, p. 131-154, 2000. 